\title{
The effect of succinate dehydrogenase inhibitor/azole mixtures on selection of Zymoseptoria tritici isolates with reduced sensitivity
}

Article

Accepted Version

Dooley, H., Shaw, M. W., Spink, J. and Kildea, S. (2016) The effect of succinate dehydrogenase inhibitor/azole mixtures on selection of Zymoseptoria tritici isolates with reduced sensitivity. Pest Management Science, 72 (6). pp. 1150-1159. ISSN 1526-4998 doi: https://doi.org/10.1002/ps.4093 Available at https://centaur.reading.ac.uk/41770/

It is advisable to refer to the publisher's version if you intend to cite from the work. See Guidance on citing.

To link to this article DOI: http://dx.doi.org/10.1002/ps.4093

Publisher: Wiley

All outputs in CentAUR are protected by Intellectual Property Rights law, including copyright law. Copyright and IPR is retained by the creators or other copyright holders. Terms and conditions for use of this material are defined in the End User Agreement. 


\section{CentAUR}

Central Archive at the University of Reading

Reading's research outputs online 


\section{Detection of SDHI insensitivity in a Zymoseptoria tritici field}

2 population carrying the $S d h C-\mathrm{H} 152 \mathrm{R}$ and $S d h D-\mathrm{R} 47 \mathrm{~W}$

\section{Substitutions}

5 Hilda Dooley $^{\mathrm{ab}}$, Mike W Shaw ${ }^{\mathrm{b}}$, Jeanne Mehenni-Ciz ${ }^{\mathrm{a}}$, John Spink ${ }^{\mathrm{a}}$ and Steven Kildea ${ }^{\mathrm{a}}$

a Department of Crop Science, TEAGASC Crops, Environment and Land Use Programme, Oak

$8 \quad$ Park, Carlow, Rep. of Ireland

9 bshool of Agriculture, Policy and Development, University of Reading, Whiteknights, 10 Reading, RG6 6AR, UK.

11 Email: stephen.kildea@teagasc.ie

12 Tel: +353599170288

\section{Abstract}

14 BACKGROUND: Succinate dehydrogenase inhibitor fungicides are important in the management of Zymoseptoria tritici in wheat. New active ingredients from this group of 16 fungicides have been introduced recently and are widely used. Because the fungicides act at a 17 single enzyme site, resistance development in Z. tritici is classified as medium-to-high risk. RESULTS: Isolates from Irish experimental plots in 2015 were tested against the SDHI

19 penthiopyrad during routine monitoring. The median of the population was approximately $2 \mathrm{x}$ 20 less sensitive than the median of the baseline population. Two of the 93 isolates were much 
1 less sensitive to penthiopyrad than least sensitive of the baseline isolates. These isolates were

2 also insensitive to most of commercially available SDHIs. Analysis of the succinate

3 dehydrogenase coding genes confirmed the presence of the substitutions $S d h C-\mathrm{H} 152 \mathrm{R}$ and

$4 \quad S d h D-\mathrm{R} 47 \mathrm{~W}$ in the very insensitive isolates.

5 CONCLUSION: This is the first report showing that the $S d h C$-H152R mutation detected in

6 laboratory mutagenesis studies also exists in the field. The function and relevance of this 7 mutation, combined with $S d h D-\mathrm{R} 47 \mathrm{~W}$, still needs to be determined.

\section{$8 \quad 1$ Introduction}

9 Throughout north-western Europe, realising potential winter wheat yields is dependent on the management of diseases, most notably septoria tritici blotch (STB). Caused by the ascomycete pathogen Zymoseptoria tritici (synonym Mycosphaerella graminicola), STB can reduce yields by up to 50\%. ${ }^{1}$ At present, control of STB is achieved through the timely application of

13 fungicides. In European Z. tritici populations, resistance to the QoI fungicides, ${ }^{2,3}$ in addition 14 to declining azole sensitivity, ${ }^{4}$ has developed over the last 10-15 years. Currently, control of STB is heavily dependent on the succinate dehydrogenase inhibitors (SDHIs), azole mixtures, and multi-site acting fungicides such as chlorothalonil and folpet, all of which are used in combination. In addition to the loss of azole sensitivity, the future availability of azoles is in doubt due to EU regulations, ${ }^{5}$ so STB control is expected to become increasingly reliant on the SDHI fungicides. Five active ingredients from this group of fungicides are now registered in northern Europe as foliar fungicides for use on cereals; bixafen, boscalid, fluxopyroxad, isopyrazam and penthiopyrad.

SDHIs inhibit fungal respiration by disrupting the functioning of the succinate dehydrogenase $(S d h)$ enzyme within the pathogens' mitochondria, and they provide a broad 
1 spectrum of disease control in a wide range of crops including cereals. ${ }^{6}$ The specific nature of

2 this control does, however, pose risks for the development of resistance in the target pathogens,

3 and for this reason they are regarded as at a medium-to-high risk of resistance development. ${ }^{7}$

4 To date there are reported to be 12 plant pathogens of economic importance which have

5 developed some level of field resistance to the SDHIs, with resistance induced in an additional

6 two pathogens under laboratory conditions. ${ }^{8}$ Field resistance has resulted from mutations in

7 one or more of the $S d h B, S d h C$ or $S d h D$ subunits ( $S d h$ enzyme). More than 27 different

8 mutations have been identified across these different pathogens, including alternative amino

9 acids at the same codon position, and depending on the pathogen, mutation and individual

10 active ingredient, resistance factors can vary from low to extremely high. ${ }^{6}$

11 To gain further insights into potential molecular mechanisms of resistance to the SDHIs

12 in Z. tritici, laboratory induced resistant mutants have been analysed by several groups. ${ }^{9-12}$ In

13 those studies mutations in one or all of the three subunits were found and the most commonly

14 identified mutations included $S d h B-\mathrm{H} 267 \mathrm{Y}, S d h C-\mathrm{A} 84 \mathrm{~V}$ and $S d h C-\mathrm{H} 152 \mathrm{R}$. However, the

15 effects of the different mutations on sensitivity depended on the SDHI used and, in some

16 instances, on the genetic background of the Z. tritici isolates tested. Mutations at some of the

17 codons identified in the mutagenesis studies have been identified in field strains ( $S d h B-\mathrm{N} 225 \mathrm{~T}$,

$18 S d h C$-T79N, and $S d h C$-N86S) in different locations throughout north-western Europe,

19 although resistance factors have been reported to be low. ${ }^{8}$

In 2015, during monitoring of a Z. tritici field population from an experimental trial against the SDHI penthiopyrad, isolates exhibiting decreased SDHI sensitivity were discovered. A selection of isolates from that population was further examined and compared to a larger collection, representing populations prior to the recent commercialisation of the $3^{\text {rd }}$ generation SDHI fungicides, to confirm their sensitivity and potential cause of insensitivity. 


\section{$1 \quad 2$ Materials \& Methods}

\section{$2 \quad 2.1$ Origin of strains}

3 Winter wheat plots of the variety Cordiale, treated with the SDHI penthiopyrad, the azole

4 prothioconazole or the multi-site folpet, were randomly sampled for Z. tritici infected leaves.

5 From these, 93 strains were isolated and their sensitivity to the SDHI fungicide penthiopyrad 6 determined as described by Dooley et al. ${ }^{13}$ Eight of these isolates were selected from that 7 collection based on sensitivity to penthiopyrad (Figure 1). Four were highly sensitive with $8 \mathrm{EC}_{50}$ values within the baseline range $\left(\mathrm{EC}_{50}\right.$ values $\left.<1.6 \mathrm{mg} / \mathrm{l}\right)$, two had moderate sensitivity 9 (EC $\mathrm{E}_{50}$ values slightly above the highest $\mathrm{EC}_{50}$ in the baseline range, $\left.>1.6 \mathrm{mg} / \mathrm{l}\right)$ and two had low 10 sensitivity $\left(\mathrm{EC}_{50}\right.$ values $\left.>30 \mathrm{mg} / \mathrm{l}\right)$.

The baseline sensitivity was based on a collection of 209 field isolates from the years 2005-2010. Sample sizes were: $2005, \mathrm{n}=26 ; 2006, \mathrm{n}=36 ; 2007, \mathrm{n}=19 ; 2009, \mathrm{n}=80 ; 2010$, $\mathrm{n}=48$. Isolates came from commercial fields, representing 21 locations in Ireland, and four

14 locations in the UK for comparison. The UK isolates (courtesy of J. Blake, ADAS) were collected in 2010 only.

\subsection{Fungicide sensitivity}

17 Sensitivity of the whole 2015 collection was determined to penthiopyrad initially, using a microtitre plate assay as described by Dooley et al. ${ }^{13}$ Sensitivity of eight selected strains representing the range of sensitivities present was determined to boscalid, bixafen, fluopyram, fluxapyroxad, isopyrazam, and penthiopyrad using the same assay used for the initial screen but with a greater range of test concentrations: from 0 to $100 \mathrm{mg} / \mathrm{l}$ with 12 dilutions, and plates were replicated three times. The sensitivity of all baseline isolates was determined to the same six SDHIs mentioned above using the same assay with appropriate concentration adjustments. 
1 Following incubation, sensitivity of each isolate was determined by assessing fungal growth, measured as light absorbance at $405 \mathrm{~nm}$ using Synergy-HT plate reader and Gen5 ${ }^{\mathrm{TM}}$ microplate software (BioTek Instruments, Inc., USA) and subsequently expressed as the fungicide concentration inhibiting growth by $50 \%\left(\mathrm{EC}_{50}\right)$ by fitting a logistic curve to percentage inhibition data using XLfit (IDBS Inc., UK). Standard error was calculated for the $\mathrm{EC}_{50}$ values

6 of the eight individual isolates.

All statistical analyses were carried out using GenStat V 14.1.0. For the baseline collection the Shapiro-Wilk test was used to test for normality. A randomisation test was used to estimate the probability that the two most insensitive isolates found would be found in the 2015 sample if there were actually a constant frequency in all samples.

\subsection{Sequence analysis of $S d h B, S d h C$, and $S d h D$ subunits}

12 The DNA sequences of the eight isolates from 2015 and a subset of 96 isolates (46\% of the 13 baseline collection) from the baseline collection were determined. Baseline isolates were chosen based on their sensitivity $\left(\mathrm{EC}_{50}\right.$ value) to isopyrazam. From each of the five years 19 strains were chosen, six of which had low, seven had medium and six had high Isopyrazam $\mathrm{EC}_{50}$ values relative to that year's collection. DNA extraction, $\mathrm{PCR}$ amplification, sequencing of each subunit and analysis was performed as previously described by Dooley et al. ${ }^{13}$ with the exception that both forward and reverse primers were used to sequence the 2015 isolates.

\section{Results}

\section{$20 \quad 3.1$ Sensitivity of isolates}

21 A wide range of sensitivities to the SDHI fungicide penthiopyrad (between 0.02 and $>30 \mathrm{mg} / \mathrm{l}$ ) was observed amongst the 93 field isolates from 2015 (Figure 1). The median sensitivity of 
1 the 2015 collection shifted towards $\mathrm{EC}_{50}$ values about $50 \%$ greater than the baseline, from $\mathrm{EC}_{50}$

2 values of $0.163 \mathrm{mg} / \mathrm{l}$ to $0.26 \mathrm{mg} / \mathrm{l}$, and the distribution was bi-modal (Figure 1). The sensitivity

3 to the other SDHIs of the eight isolates tested further was, with the exception of fluopyram,

4 consistent with the response to penthiopyrad (Table 1). Isolates initially selected as highly

5 sensitive to penthiopyrad had sensitivities similar to the mean/median baseline sensitivity of

6 the other SDHIs, again with the exception of fluopyram (see Table 2 for baseline sensitivity).

7 Those with moderate sensitivity were individually within the baseline normal or skewed

8 normal distributions (see Table 2 for baseline sensitivity). The two isolates initially selected

9 as having very low sensitivity to penthiopyrad had high resistance factors (Table 1) and did not

10 lie in the original normal distributions, where applicable $\left(P<0.001\right.$ for $\mathrm{EC}_{50}$ to all fungicides

11 except fluopyram on the null hypothesis of a normal distribution). Although both less sensitive

12 isolates were found in 2015 , there is no convincing evidence for any increase in frequency in

13 the field since the start of commercial use of SDHI fungicides $(P=0.094$ by direct calculation

14 or randomisation test). However, the 2015 sample distribution as a whole is less sensitive than

15 the baseline (Kolmogorov 2-sample test, $D=0.31, P<0.001$ )

\section{$16 \quad 3.2$ Variation in the $S d h$ subunits of isolates}

17 In the eight isolates from 2015 only a single synonymous substitution was observed in the $S d h B$

18 subunit. A large number of variations were observed in the $S d h C$ subunit, however only five

19 of these resulted in changes in the target protein (Table 1). The amino acid substitutions $S d h C$ -

$20 \mathrm{R} 13 \mathrm{P}, S d h C$-N33T and $S d h C$-N34T had no observable impact on SDHI sensitivity as 21 measured; $S d h C$-N33T and $S d h C$-N34T were detected widely within the baseline collection

22 (Table 3); SdhC-N79T was detected in a single strain and associated with medium levels of

23 SDHI sensitivity. The isolates OP15.13 and OP15.15, both displaying high resistance factors 
1 towards penthiopyrad and other SDHIs, contained the $S d h C-\mathrm{H} 152 \mathrm{R}$ and $S d h D-\mathrm{R} 47 \mathrm{~W}$

2 substitutions.

\section{Discussion}

4 The six 2015 isolates selected as moderately sensitive or highly sensitive were similar to 5 baseline isolates in both sensitivity and mutation spectrum. The $S d h C$-N79T mutation was 6 present in one of these moderately sensitive isolates, confirming the low resistance factors 7 previously reported by FRAC. ${ }^{8}$ The two isolates which had the mutations $S d h C-\mathrm{H} 152 \mathrm{R}$ and 8 SdhD-R47W were extremely insensitive to all SDHIs, with the exception of fluopyram. This

9 cross-resistance amongst SDHIs was also seen in the baseline data (data not shown) and is in 10 agreement with Fraaije et al. ${ }^{11}$ who found clear positive correlations between different SDHIs, 11 and Schürch and Cordette ${ }^{14}$ who found similar patterns but with weaker relationships. The $12 S d h C$-H152R mutation has previously been identified by both Stammler et al. ${ }^{10}$ and Scalliet et 13 al. ${ }^{12}$ in mutagenesis studies; the latter reporting high resistance factors to the majority of newer 14 SDHIs. The incomplete cross-resistance between fluopyram and the other SDHIs, which was 15 observed in the baseline data (data not shown), was also demonstrated by Scalliet et al, ${ }^{12}$ who 16 found that an isolate with the $S d h C-\mathrm{H} 152 \mathrm{R}$ mutation which grew in the presence of boscalid 17 and isopyrazam, was all but restricted in the presence of fluopyram. This incomplete crossresistance has also been demonstrated in other pathogens such as Alternaria alternate, ${ }^{15} \mathrm{~A}$. solani, ${ }^{16}$ Botrytis cinerea, ${ }^{17}$ and Corynespora cassicola ${ }^{18}$.

This is the first finding of $S d h C-\mathrm{H} 152 \mathrm{R}$ in a $Z$. tritici field population, and as such represents an important development. Whilst Scalliet et al. ${ }^{12}$ demonstrated the mutation $S d h C$ H152R did not affect the ability of $Z$. tritici laboratory mutated strains to infect and cause disease, they did report a reduction in enzyme activity. As our isolates were retrieved from the 
1 field at a frequency $(0.66 \%, 95 \%$ CI $0.08 \%-1.8 \%)$ much larger than the mutation rate (typically

2 less than $10^{-9}$ for point mutations), they must be able to infect and cause disease. Whether they

3 suffer a fitness penalty, and what role if any the mutation $S d h D-\mathrm{R} 47 \mathrm{~W}$ plays, remains to be

4 determined.

Irrespective of potential fitness penalties it must be assumed that the continued

widespread use of SDHIs is likely to result in an increase in frequency of the alleles associated

with high resistance factors because of the very strong selection imposed by good current control levels. ${ }^{19}$ Such an increase will adversely affect the efficacy of those SDHIs currently available as foliar applied products for STB control. Currently the SDHIs are an essential tool in the control of STB in in north-western Europe. It is imperative that all available measures are taken to maintain their excellent field performance against $Z$. tritici for as long as possible.

Continued monitoring of $Z$. tritici field populations is essential to be able to identify changes in sensitivity and mutations which cause those changes. Fungicide resistance management strategies, such as reductions in the number of applications of active ingredients from a single group and mixing with effective fungicide partners, ${ }^{20}$ particularly multi-site acting fungicides, must be used to help slow the selection of resistant strains. Disease incidence should be reduced by using host resistance ${ }^{21,22}$ and any proven agronomic practices which reduce $Z$. tritici population growth rates during the period of application of fungicide implemented, since they will reduce the rate of selection. ${ }^{23-25}$

\section{Acknowledgements}

21 The authors would like to thank Liz Glynn and Jim Grace from Teagasc, and student Aurélien Lepennetier for their help with laboratory testing. This research has been funded by Teagasc under the Walsh Fellowship scheme and the Irish Department of Agriculture, Food and Marine 24 under their research stimulus fund, grant number 11S113. 
References

I. Burke, J. J. \& Dunne, B., Field testing of six decision support systems for scheduling fungicide applications to control Mycosphaerella graminicola on winter wheat crops in Ireland. Journal of Agricultural Science, I 46 (2008) 4I5-428.

2. $\quad$ Fraaije, B. A., Lucas, J. A., Clark, W. S. \& Burnett, F. J., In Proceedings British Crop Protection Council International Congress- Crop Science \& Technology, 2. The British Crop Protection Council, Alton, Hampshire, UK, 2003, pp. 689-694.

3. O'Sullivan, E., In Teagasc End of Year Report 5078. Teagasc, 2009, pp. I-I6.

4. Stammler, G. \& Semar, M., Sensitivity to Mycosphaerella graminicola (anamorph: Septoria tritici) to DMI fungicides across Europe and impact on field performance. EPPO Bulletin, $4 \mathrm{I}$ (20II) I49-I55.

5. Jess, S., Kildea, S., Moody, A., Rennick, G., Murchie, A. K. \& Cooke, L. R., European Union policy on pesticides: implications for agriculture in Ireland. Pest Management Science, 70 (2014) 1646-1654.

6. Sierotzki, H. \& Scalliet, G., A review of current knowledge of resistance aspects for the nextgeneration succinate dehydrogenase inhibitor fungicides. Phytopathology, 103 (2013) 880-887.

7. Anon, 20I4. FRAG, http://www.pesticides.gov.uk/Resources/CRD/MigratedResources/Documents/F/frag-sdhi-statement-cereals-april-20I4.pdf, 2014.

8. Anon, 20I5. FRAC, http://www.frac.info/docs/default-source/sdhi-wg/minutes-of-the-20l4sdhi-meeting-recommendations-for-20I5-v2.pdf?sfvrsn=4, 2014.

9. Skinner, W., Bailey, A., Renwick, A., Keon, J., Gurr, S. \& Hargreaves, J., A single amino-acid substitution in the iron-sulphur protein subunit of succinate dehydrogenase determines resistance to carboxin in Mycosphaerella graminicola. Current Genetics, 34 (1998) 393-398.

10. Stammler, G., Glattli, A., Koch, A. \& Schlehuber, S., In Modern Fungicides and Antifungal Compounds VI, ed. H. W. Dehne, H. B. Deising, U. Gisi, K. H. Kuck, P. E. Russell \& H. Lyr, Reinhardsbrunn, Friedrichroda, Germany, 201I, pp. 195-198.

II. Fraaije, B. A., Bayon, C., Atkins, S., Cools, H. J., Lucas, J. A. \& Fraaije, M. W., Risk assessment studies on succinate dehydrogenase inhibitors, the new weapons in the battle to control Septoria leaf blotch in wheat. Molecular Plant Pathology, 13 (20I2) 263-275.

12. Scalliet, G., Bowler, J., Luksch, T., Kirchhofer-Allan, L., Steinhauer, D., Ward, E., Niklaus, M., Verras, A., Csukai, M., Daina, A. \& Fonne-Pfister, R., Mutagenesis and functional studies with succinate dehydrogenase inhibitors in the wheat pathogen Mycosphaerella graminicola. PLoS ONE, 7 (2012) e35429.

13. Dooley, H., Shaw, M. W., Spink, J. \& Kildea, S., The effect of succinate dehydrogenase inhibitor/azole mixtures on selection of Zymoseptoria tritici isolates with reduced sensitivity. Pest Management Science, Early View (20I5).

14. Schürch, S. \& Cordette, T., Grundempfindlichkeit der Septoria-Blattdürre des Weizens gegenüber den SDHI-Fungiziden. Agrarforschung Schweiz, 4 (2013) 82-87.

15. Avenot, H. F. \& Michailides, T. J., Progress in understanding moleular mechanisms and evolution of resistance to succinate dehydrogenase inhibiting (SDHI) fungicides in phytopathogenic fungi. Crop Protection, 29 (2010) 643-65I.

16. Gudmestad, N. C., Arabiat, S., Miller, J. S. \& Pasche, J. S., Prevalence and impact of SDHI fungicide resistance in Alternaria solani. Plant Disease, 97 (2013) 952-960.

17. Stammler, G., Wolf, A., Glaettli, A. \& Klappach, K., Respiration inhibitors: Complex II. In Fungicide Resistance in Plant Pathogens: Principles and a Guide to Practical Management(eds.) $\mathrm{H}$. Ishii \& D. W. Hollomon. Springer Japan, Tokyo, 2015, pp. I05-II7. 
18. Ishii, H., Miyamoto, T., Ushio, S. \& Kakishima, M., Lack of cross-resistance to a novel succinate dehydrogenase inhibitor, fluopyram, in highly boscalid-resistant isolates of Cornespora cassiicola and Podosphaera xanthii. Pest Management Science, 67 (20II) 474-482.

19. van den Bosch, F., Paveley, N., Shaw, M., Hobbelen, P. \& Oliver, R., The dose rate debate: does the risk of fungicide resistance increase or decrease with dose? Plant Pathology, 60 (20II) 597606.

20. van den Bosch, F., Oliver, R., van den Berg, F. \& Paveley, N., Governing principles can guide fungicide-resistance management tactics. Annual Review of Phytopathology, 52 (2014) I75-I 95.

21. Miedaner, T., Zhao, Y., Gowda, M., Longin, C. F., Korzun, V., Ebmeyer, E., Kazman, E. \& Reif, J., Genetic architecture of resistance to Septoria tritici blotch in European wheat. BMC Genomics, 14 (20I3) 858.

22. Gigot, C., Saint-Jean, S., Huber, L., Maumené, C., Leconte, M., Kerhornou, B. \& de VallavieillePope, C., Protective effects of a wheat cultivar mixture against splash-dispersed septoria tritici blotch epidemics. Plant Pathology, 62 (2013) I0II-1019.

23. Suffert, F., Sache, I. \& Lannou, C., Early stages of septoria tritici blotch epidemics of winter wheat: build-up, over seasoning, and release of primary inoculum. Plant Pathology, 60 (201I) I66-I77.

24. Simón, M. R., Cordo, C. A., Perelló, A. E. \& Struik, P. C., Influence of nitrogen supply on the susceptibility of wheat to Septoria tritici. Journal of Phytopathology, I 5 I (2003) 283-289.

25. Gladders, P., Paveley, N. D., Barrie, I. A., Hardwick, N. V., Hims, M. J., Langton, S. \& Taylor, M. C., Agronomic and meteorological factors affecting the severity of leaf blotch caused by Mycosphaerella graminicola in commercial wheat crops in England. Annals of Applied Biology, I 38 (200I) 30I-3II. 
2 Figure 1 Frequency distribution of baseline isolates $(n=209)$ and 2015 isolates $(n=93)$ to the

3 SDHI fungicide penthiopyrad. Re-tested isolates for which $S d h$ sequence was obtained are $4 \quad$ marked by arrows. 